\title{
Device Incorrectly Reprocessed
}

National Cancer Institute

\section{Source}

National Cancer Institute. Device Incorrectly Reprocessed. NCI Thesaurus. Code C139575.

Problems associated with the failure to properly and adequately reprocess the device. 